\title{
Activity of two key toxin groups in Australian elapid venoms show a strong correlation to phylogeny but not to diet
}

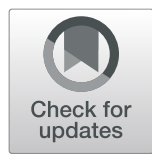

Theo Tasoulis', Michael S. Y. Lee ${ }^{2,3}$, Manon Ziajko ${ }^{1}$, Nathan Dunstan ${ }^{4}$, Joanna Sumner ${ }^{5}$ and Geoffrey K. Isbister ${ }^{1 *}$ (D)

\begin{abstract}
Background: The relative influence of diet and phylogeny on snake venom activity is a poorly understood aspect of snake venom evolution. We measured the activity of two enzyme toxin groups - phospholipase $A_{2}\left(P L A_{2}\right)$, and L-amino acid oxidase (LAAO) - in the venom of 39 species of Australian elapids (40\% of terrestrial species diversity) and used linear parsimony and BayesTraits to investigate any correlation between enzyme activity and phylogeny or diet.

Results: PLA 2 activity ranged from 0 to $481 \mathrm{nmol} / \mathrm{min} / \mathrm{mg}$ of venom, and LAAO activity ranged from 0 to 351 $\mathrm{nmol} / \mathrm{min} / \mathrm{mg}$. Phylogenetic comparative methods, implemented in BayesTraits showed that enzyme activity was strongly correlated with phylogeny, more so for LAAO activity. For example, LAAO activity was absent in both the Vermicella and Pseudonaja/Oxyuranus clade, supporting previously proposed relationships among these disparate taxa. There was no association between broad dietary categories and either enzyme activity. There was strong evidence for faster initial rates of change over evolutionary time for LAAO (delta parameter mean 0.2), but no such pattern in $\mathrm{PLA}_{2}$ (delta parameter mean 0.64). There were some exceptions to the phylogenetic patterns of enzyme activity: different PLA 2 activity in the ecologically similar sister-species Denisonia devisi and D. maculata; large interspecific differences in PLA 2 activity in Hoplocephalus and Austrelaps.

Conclusions: We have shown that phylogeny is a stronger influence on venom enzyme activity than diet for two of the four major enzyme families present in snake venoms. PLA $A_{2}$ and LAAO activities had contrasting evolutionary dynamics with the higher delta value for PLA $\mathrm{A}_{2}$ Some species/individuals lacked activity in one protein family suggesting that the loss of single protein family may not incur a significant fitness cost.
\end{abstract}

Keywords: Snake, Evolution, Phylogeny, Venom, Snake venom, Toxin, Diet, Phospholipase

\section{Introduction}

Venomous snakes in Australia belong almost entirely to the front-fanged family Elapidae. The diversity of this family is the result of a continental scale adaptive radiation thought to be approximately 25 million years old [1]. This entire Australasian radiation (including New Guinea and the Solomons), currently consists of approximately 120 terrestrial and more than 60 marine species of snakes [2]. A recent phylogeny divided the Australasian elapid radiation into 11 major clades [1]. Demansia, Furina/Cacophis, Simoselaps/Brachyurophis, Acanthophis, Pseudechis,

\footnotetext{
* Correspondence: Geoff.isbister@gmail.com

${ }^{1}$ Clinical Toxicology Research Group, University of Newcastle, Newcastle, New South Wales 2308, Australia

Full list of author information is available at the end of the article
}

Rhinoplocephalus/Suta, Vermicella, Pseudonaja/Oxyuranus, Notechis, Hemiaspis and Hydrophiini (viviparous sea snakes) (Fig. 1).

Snake venoms are mixtures of different protein families. A recent review of snake venom proteomes globally [3], identified four major and six secondary protein families that account for the majority of proteins in both elapid and viperid venoms. Australasian elapid venoms contain all four major protein families; three-finger toxins (3FTx), phospholipase A2 (PLA2), snake venom serine protease (SVSP), and snake venom metalloprotease (SVMP) - and all six secondary protein families; disintegrin (DIS), L-amino acid oxidase (LAAO), natriuretic peptides (NP), kunitz peptides (KUN) cysteine-rich secretary proteins (CRiSP) and C-type lectins (CTL) [3]. These protein families are typically unevenly

(c) The Author(s). 2020 Open Access This article is distributed under the terms of the Creative Commons Attribution 4.0 International License (http://creativecommons.org/licenses/by/4.0/), which permits unrestricted use, distribution, and 


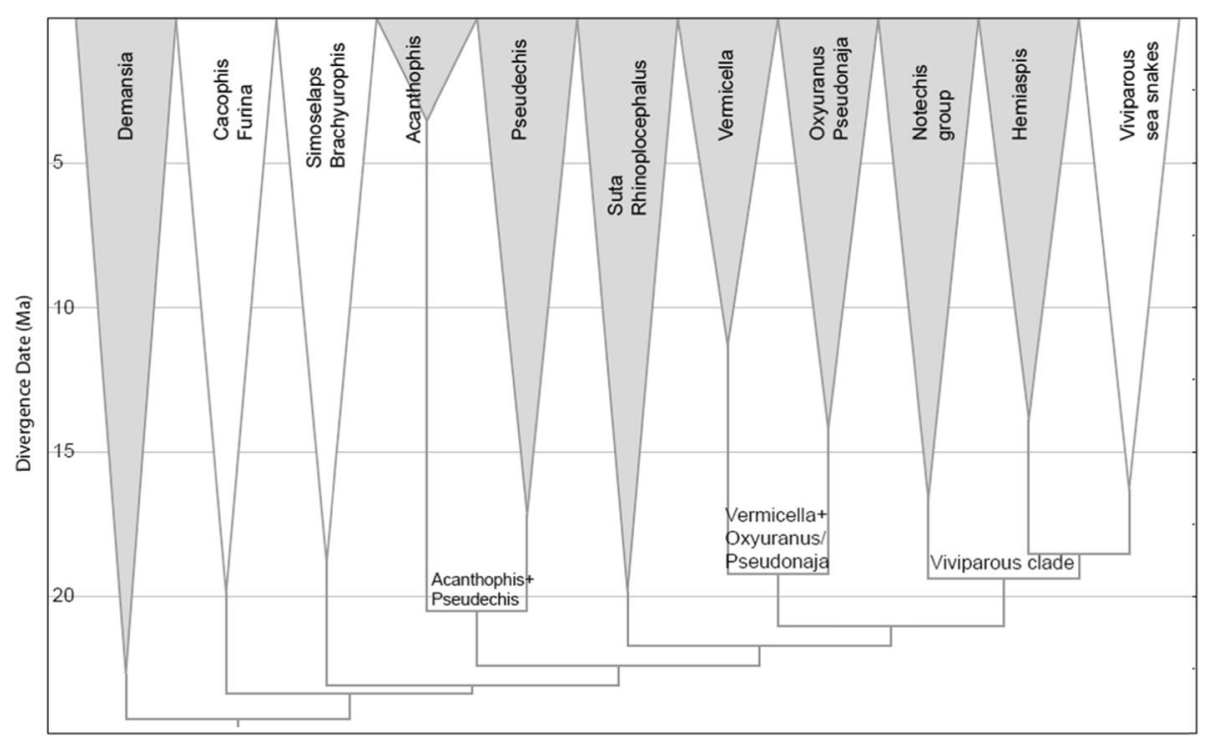

Fig. 1 Phylogeny of Australian elapids showing the 11 major clades. The eight shaded clades were sampled in this study

represented in the venom proteome of a particular species. We identified two protein families of interest, the major protein family PLA $\mathrm{P}_{2}$, and the secondary protein family LAAO. These particular protein families were chosen as of the 10 major protein families present in snake venoms, only four are enzymatic. Two of these (SVMP and SVSP) were not included in the study. SVMP is not a major component of Australasian snake venoms, while SVSP is a protein family with multiple sites of enzyme activity which would require multiple different types of assays. PLA2s can be mono or multimeric with a molecular mass of 12 to $18 \mathrm{kDa}$ per monomer [4-7]. They have a highly diverse toxicological profile - including pre-synaptic neurotoxicity $[5,7]$, myotoxicity [8] and anticoagulant activity [9]. PLA2 enzymes catalyze the hydrolysis of the ester bond at the $s n-2$ positon of glycerophospholipids releasing lysophospholipids and fatty acids [4]. The toxic effects of LAAO proteins are imperfectly understood as the literature contains conflicting reports $[10,11]$. However, its three-dimensional structure and biochemistry have been elucidated. LAAO is a homodimer with the molecular mass of each monomer being 50 to 70 $\mathrm{kDa}$ [12]. LAAO oxidizes an amino acid substrate to form an imino acid which then undergoes non-enzymatic hydrolysis yielding $\alpha$-keto acid and ammonia. The first step of this process causes a reduction of flavin adenine dinucleotide (FAD) which is then oxidized in the presence of molecular oxygen to form $\mathrm{H}_{2} \mathrm{O}_{2}$ [12].

Studies on snake venom evolution have largely focussed on comparing the sequence similarity of amino acids in homologous toxins between related snake species (eg. 3FTxs in the colubrid Boiga [13], and Australian elapids [14, 15], $\mathrm{PLA}_{2} \mathrm{~S}$ in the viperids - Vipera [16], Gloydius [17] and Crotalus [7]), and tracing the molecular evolution of toxins among and between snake genera (eg. SVMPs $[18,19]$ and CRiSPs [20]). Far less is understood about the temporal dynamics of snake venom evolution, whether venom composition is more strongly influenced by phylogeny or diet, and the importance of genetic drift in snake venom evolution. By combining published studies on venom proteomes with published phylogenies it can be shown that the venoms of some snake genera co-vary with phylogenetic distance. An example of this is the venom proteomes of the viper genus Bitis [21], which closely mirror the phylogeny of this genus as proposed by Wittenberg et.al [22]. .Several studies have demonstrated prey-specific toxicity in snake venom [23, 24]. An example of this is the prey specific venom of the colubrid snake Boiga irregularis which has been shown to be highly toxic to birds and lizards - its primary prey [25], while being far less toxic to mammals [26]. Conversely one study on an Australian elapid (Notechis scutatus), showed no correlation between venom and diet [27], and suggested that genetic drift was responsible for observed variation in venom profiles [28].

The Australasian elapid radiation presents an excellent opportunity to investigate the complexities and temporal dynamics of snake venom evolution as it is extremely speciose, and contains species with highly divergent morphological and dietary specializations. This radiation includes species that have adapted to an extreme range of habitats, from deserts to rainforests and tropical grasslands to subalpine woodlands. The diet of Australian elapids is well understood as a result of a series of studies by Shine (e.g. [29, 30], see Additional file 1: Table S1. Supplementary section). Lizards are a major part of the diet of most snake genera/species, particularly the lizard family Scincidae [29, 31-34] . There have been several adaptive moves away from a dietary 
reliance on lizards,- resulting in snake species that specialize in preying on frogs [30,35], mammals [36], squamate eggs [37] and other snakes [38]. In addition many Australasian elapid genera include dietary generalists [39-41].

We aimed to investigate the evolution of two protein families, $\mathrm{PLA}_{2}$ and LAAO, in Australasian elapid venoms, by measuring their enzymatic activity, and analysing this with respect to phylogeny and snake diet. The study included 90 individual snakes from 17 genera, with representatives from eight of the 11 major clades. We performed ancestral state reconstructions and evaluated their evolutionary dynamics using phylogenetic comparative methods, and compared venom activity at several taxonomic hierarchies - major clades, inter-generic and intra-generic.

\section{Results}

\section{Phospholipase $\mathrm{A}_{2}$}

$\mathrm{PLA}_{2}$ activity was measured in 90 individual snakes from 37 different species (Fig. 2). PLA2 activity values ranged from 0 to 526 nanomoles of chromophore produced per minute per $\mathrm{mg}$ of venom $(\mathrm{nmol} / \mathrm{min} / \mathrm{mg}$; averaged values for individual snakes). Activity levels were arbitrarily defined as 0 to 25 $\mathrm{nmol} / \mathrm{min} / \mathrm{mg}=$ low, 25 to $100 \mathrm{nmol} / \mathrm{min} / \mathrm{mg}=$ medium, 100 to $300 \mathrm{nmol} / \mathrm{min} / \mathrm{mg}=$ high and $>300 \mathrm{nmol} / \mathrm{min} / \mathrm{mg}=$ very high. PLA2 activity was present in all species tested, except the monotypic genus Echiopsis. The Demansia clade had high $\mathrm{PLA}_{2}$ activity, with the highest activity for the genus being $D$. torquata $(110 \mathrm{nmol} / \mathrm{min} / \mathrm{mg})$. The Acanthophis clade had medium to high PLA $\mathrm{P}_{2}$ activity. It was high in Acanthophis pyrrhus $(153 \mathrm{nmol} / \mathrm{min} / \mathrm{mg})$, and medium in A. antarcticus $(53 \mathrm{nmol} / \mathrm{min} / \mathrm{mg})$. The Pseudechis clade had the highest $\mathrm{PLA}_{2}$ activity of any clade, with the sister species Pseudechis.colletti/P.guttatus having the strongest $\mathrm{PLA}_{2}$ activity of any species - P.colletti $(480 \mathrm{nmol} / \mathrm{min} / \mathrm{mg})$ and $P$. guttatus $(481$ $\mathrm{nmol} / \mathrm{min} / \mathrm{mg}$ ). The Rhinoplocephalus/Suta clade had low to

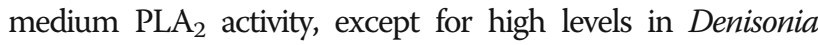
maculata venom $(294 \mathrm{nmol} / \mathrm{min} / \mathrm{mg})$ and Elapognathus coronatus venom $(118 ; \mathrm{nmol} / \mathrm{min} / \mathrm{mg})$.Only one species, Vermicella annulata was tested in the Vermicella clade which had almost no activity $(1 \mathrm{nmol} / \mathrm{min} / \mathrm{mg})$. The Pseudonaja/Oxyuranus clade had low PLA 2 activity, although Oxyuranus had higher activity than Pseudonaja. The Notechis clade had very high variability in $\mathrm{PLA}_{2}$ activity, ranging from undetectable in Echiopsis, to very high for Austrelaps ramsayi $(376 \mathrm{nmol} /$ $\mathrm{min} / \mathrm{mg}$ ). The three species in the genus Hoplocephalus showed a strong non-overlapping range of inter-specific variability in PLA $_{2}$ activity - high in H. bitorquatus (199 nmol/ $\mathrm{min} / \mathrm{mg})$, low in $H$. stephensi $(16 \mathrm{nmol} / \mathrm{min} / \mathrm{mg})$, and barely detectable in H. bungaroides $(0.73 \mathrm{nmol} / \mathrm{min} / \mathrm{mg})$.

\section{L-amino acid oxidase}

LAAO activity was measured in 90 individual snakes from 39 species (Fig. 3). LAAO activity values ranged from 0 to 410 nanomoles of $\mathrm{H}_{2} \mathrm{O}_{2}$ produced per minute per milligram

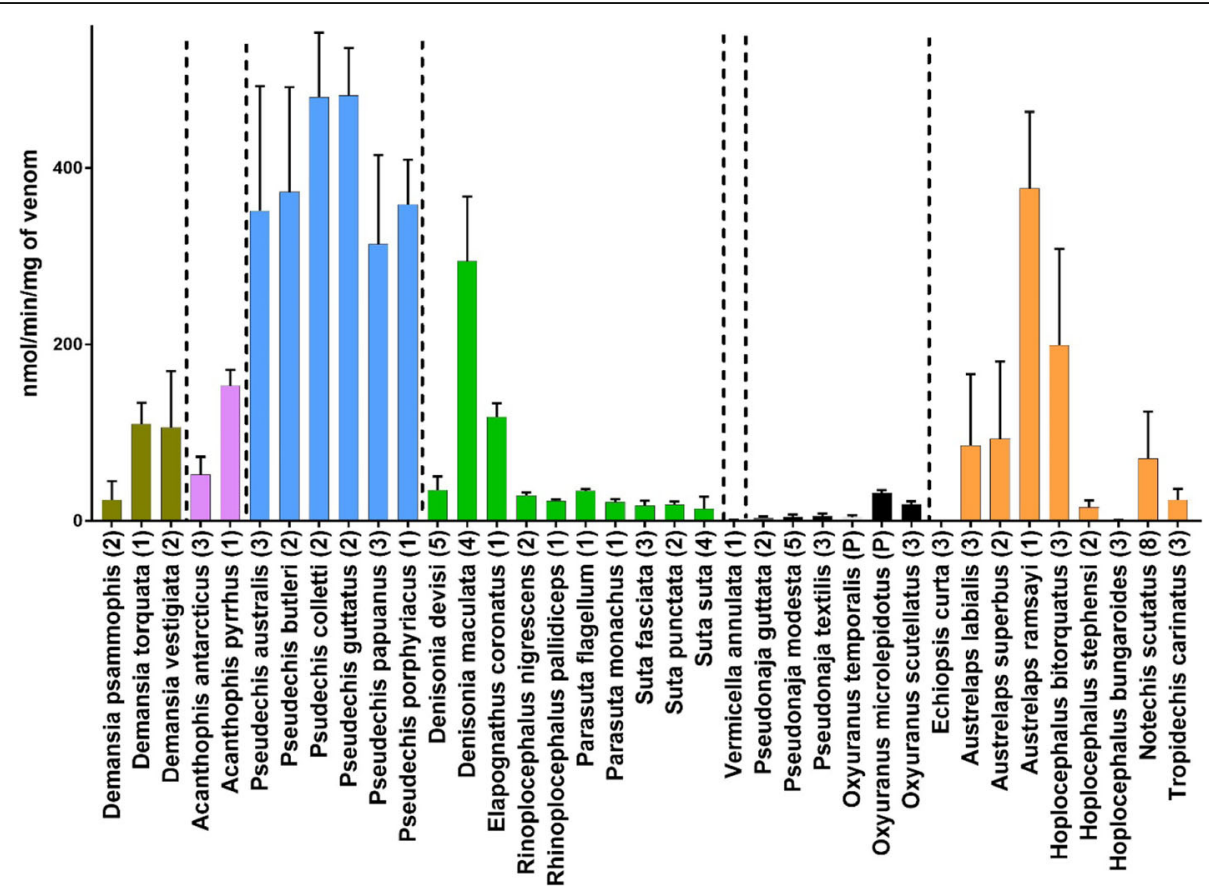

Fig. 2 A bar chart (mean with SD for technical replicates), showing PLA $A_{2}$ activity for 37 species of Australian elapids representing seven major clades. Vertical dashed lines and bar colours separate major clades as determined by Lee et.al 2016. Y-axis units are nanomoles of chromophore released per minute per milligram of venom. All assays were replicated $n=5$. Numbers in brackets indicate numbers of individuals assayed and (P) indicates pooled venom 


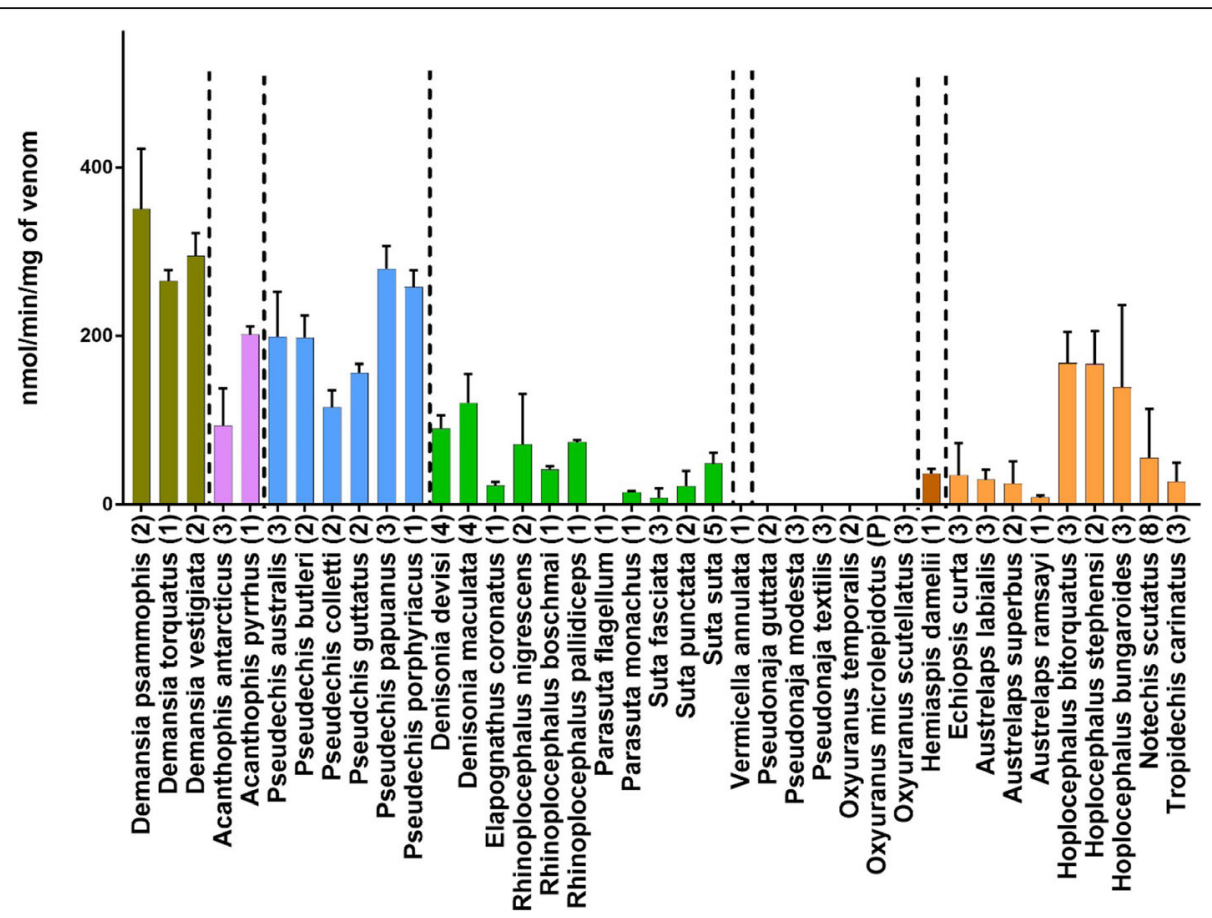

Fig. 3 A bar chart (mean with SD), showing LAAO activity for 39 species of Australian elapids representing eight major clades. Vertical dashed lines separate clades as determined by Lee et. al. 2016. Y-axis units are nanomoles of $\mathrm{H}_{2} \mathrm{O}_{2}$ released per minute per milligram of venom. All assays were replicated $n=5$. Numbers in brackets indicate numbers of individuals assayed and $(P)$ indicates pooled venom

of venom (nmol $/ \mathrm{min} / \mathrm{mg}$; averaged values for individual snakes). Activity levels were arbitrarily defined as 0 to 50 $\mathrm{nmol} / \mathrm{min} / \mathrm{mg}=$ low, 50 to $100 \mathrm{nmol} / \mathrm{min} / \mathrm{mg}=$ medium, 100 to $250 \mathrm{nmol} / \mathrm{min} / \mathrm{mg}=$ high and $>250 \mathrm{nmol} / \mathrm{min} / \mathrm{mg}=$ very high. The Demansia clade had the highest activity, particularly Demansia psammophis (351 nmol/min/mg). Activity in the Acanthophis clade was medium in A. antarcticus (94 nmol/min/mg), but high in A. pyrrhus $(201 \mathrm{nmol} / \mathrm{min} /$ $\mathrm{mg})$. The Pseudechis clade also had high LAAO activity, with P.papuanus having the highest activity in the genus (279 nmol/min/mg). The Rhinoplocephalus/Suta clade had low to medium activity (typically about $50 \mathrm{nmol} / \mathrm{min} / \mathrm{mg}$ ), with the species $D$. maculata again having the highest activity in the clade $(121 \mathrm{nmol} / \mathrm{min} / \mathrm{mg})$. Some individuals in this clade entirely lacked LAAO activity (Parasuta flagellum and Suta fasciata). Vermicella and Pseudonaja/Oxyuranus clades had no LAAO activity. LAAO activity in the Notechis clade was low for all genera (typically in the range of 25 to 30 $\mathrm{nmol} / \mathrm{min} / \mathrm{mg}$ ), with the notable exception of the genus Hoplocephalus which showed relatively high activity for all species, H. bungaroides $(139 \mathrm{nmol} / \mathrm{min} / \mathrm{mg})$, H.stephensi (167 nmol/min/mg) and H. bitorquatus (168 nmol/min/mg).

\section{Phylogenetic relationships of PLA 2 and LAAO enzyme activity}

Linear parsimony showed that there was a strong association between both PLA $\mathrm{P}_{2}$ activity and LAAO activity and the currently accepted phylogenetics of the eight major clades of elapids tested (Figs. 4 and 5).

Ancestral state reconstruction of PLA $\mathrm{P}_{2}$ estimates medium $\mathrm{PLA}_{2}$ activity levels $(29-53 \mathrm{nmol} / \mathrm{min} / \mathrm{mg}$, i.e. 1.6 to $1.8 \mathrm{log}$ transformed), at the commencement of the Australian elapid radiation. There was then an accelerated early burst of evolution at the base of the Pseudechis clade, which has been retained in all species of this clade (Fig. 4). There was also an early burst of accelerated evolution for $\mathrm{PLA}_{2}$ at the base of the Notechis clade, which occurred after the divergence of Echiopsis (in which PLA 2 activity has been lost). There was an early almost total loss of activity in the Vermicella clade. Overall, the remaining clades were stable, without changes in $\mathrm{PLA}_{2}$ activity, except for isolated taxa. There were isolated increases in $\mathrm{PLA}_{2}$ activity for Demansia vesigiata (Demansia clade), Elapognathus coronatus (Rhinoplocephalus/Suta clade), and Hoplocephalus bitorquatus (Notechis clade). Additionally there were two other instances of increased PLA $\mathrm{P}_{2}$ activity not incorporated into the tree due to lack of molecular data - Denisonia maculata and Austrelaps ramsayi (Fig. 2).

Ancestral state reconstruction for LAAO activity estimates high activity levels of $94-371 \mathrm{nmol} / \mathrm{min} / \mathrm{mg}$, i.e. 1.98-2.55 log transformed at the commencement of the Australian elapid radiation). These high activity levels remained stable in the early diverging clades Demansia and Pseudechis (Fig. 5). There was a loss of activity in the remaining clades, with a total loss of activity in the 


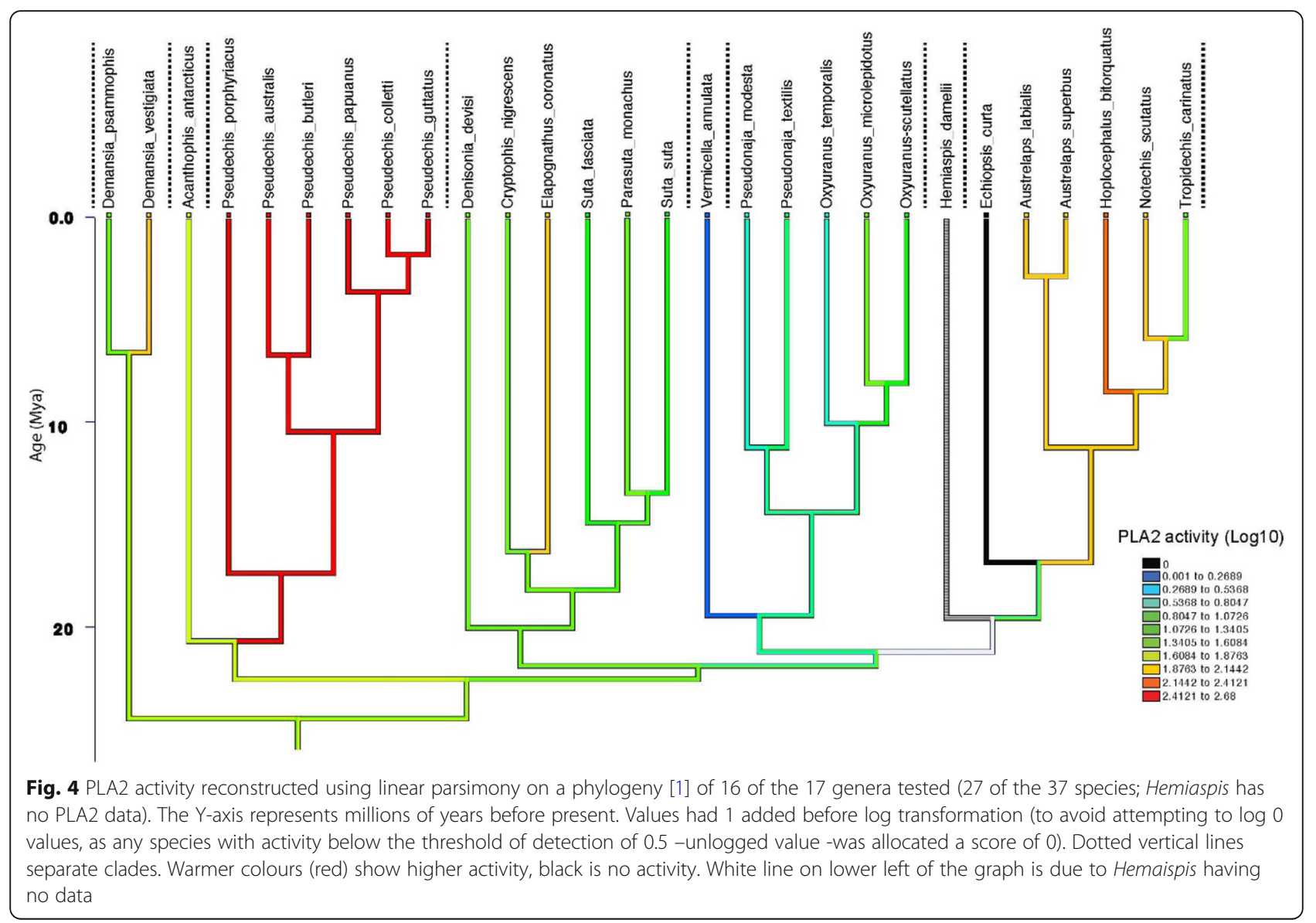

Vermicella and Pseudonaja/Oxyuranus clades, which appears to predate the divergence of these sister clades. There has been a variable reduction of LAAO activity in several taxa in the Rhinoplocephalus/Suta clade and in the Notechis clade. There has been a late burst of accelerated evolution in the genus Hoplocephalus which occurred before the subsequent speciation within this genus. This increase in activity was unique among genera in the Notechis clade.

The linear parsimony optimizations (using species means) are shown in Fig. 6; square-change parsimony (which is very similar to maximum likelihood [42]), yielded similar patterns (see Additional file 1: Figures S1 and S2). There was no evidence for accelerated rates of evolution in $\mathrm{PLA}_{2}$ with an estimated Delta parameter of 0.64 (95\% Highest Posterior Density interval [=HPD] 0.009-1.64) but strong evidence for this in LAAO with a value of 0.209 (95\% HPD 0.005-0.511) (Fig. 6). Values of less than 1 indicate faster early rates of evolution.

\section{Dietary categories and enzymatic activity}

Activity levels of PLA2 and LAAO showed no evidence of being correlated with the eight dietary categories; invertebrates, fish, frogs, lizards, snakes, mammals, birds and eggs. In nearly every comparison, the regression coefficient (beta) was close to 0 and the 95\% HPD always included 0 (Fig. 6BC). The only potential associations were a weak (i.e. non-significant) positive correlation between LAAO activity and the amounts of frogs and eggs in the diet.

\section{Discussion}

We have demonstrated a strong phylogenetic signal in $\mathrm{PLA}_{2}$ and LAAO activity in the Australian elapid radiation by measuring these enzymes in eight of the 11 currently accepted major clades. We found no relationship between $\mathrm{PLA}_{2}$ and LAAO activity and dietary preferences within this phylogenetic framework. We have also demonstrated that these two toxin families exhibit contrasting evolutionary dynamics, with LAAO characterized by early burst accelerated evolution and $\mathrm{PLA}_{2}$ showing consistent rates of evolutionary change throughout the timespan of the Australasian elapid radiation. Activity for both protein families was remarkably clade specific.

\section{PLA $A_{2}$ activity}

Our ancestral state reconstruction suggests that evolutionary rates of $\mathrm{PLA}_{2}$ activity has remained relatively constant 


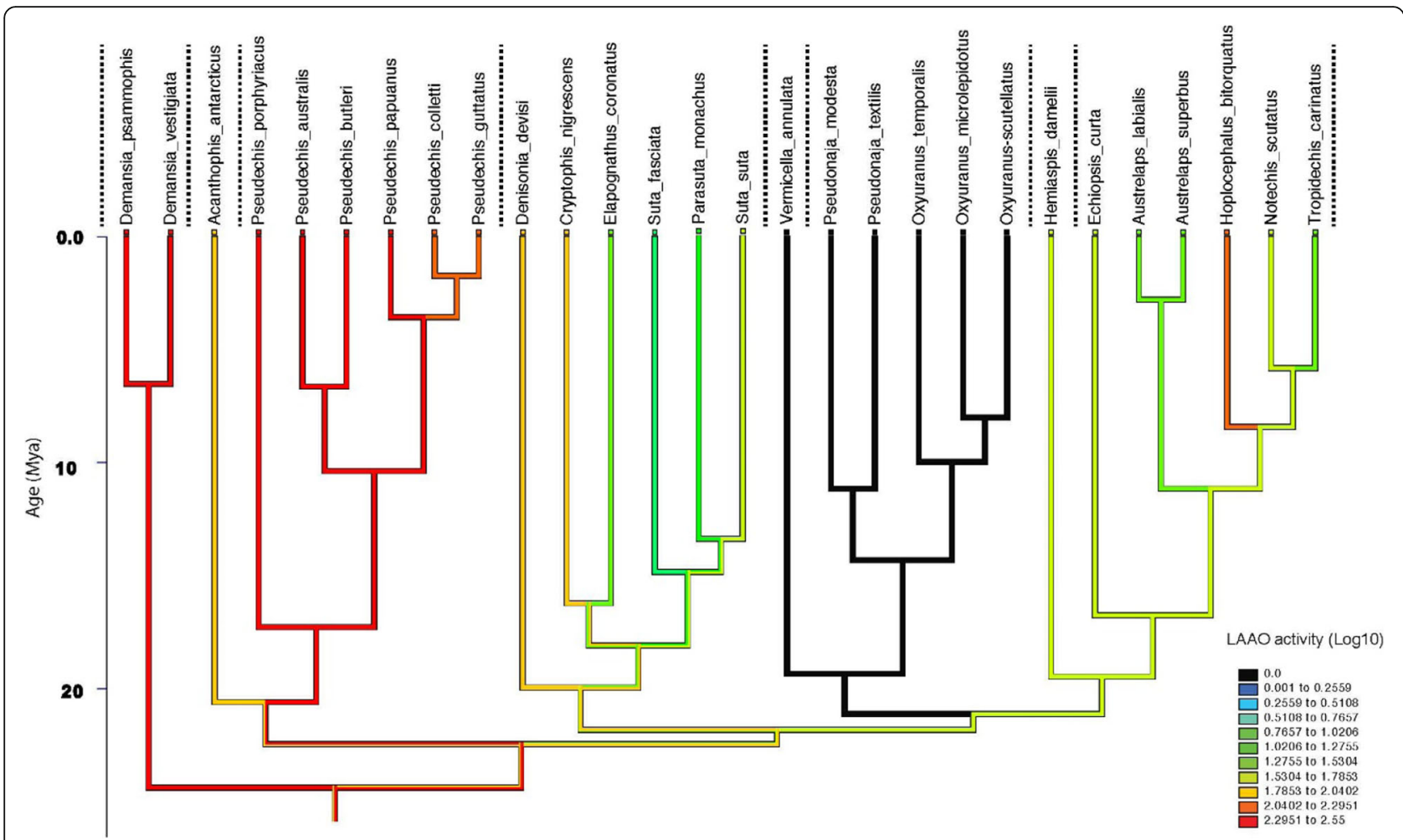

Fig. 5 LAAO activity reconstructed using linear parsimony on a phylogeny [1] for all 17 genera tested (28 of the 39 species for which activity was measured). Y-axis represents millions of years before present. Values had 1 added before log transformation (to avoid attempting to log 0 values, as any species with activity below the threshold of detection of 0.5 -unlogged value - was allocated a score of 0 ). Dotted vertical lines separate clades. Warmer colours (red) show higher activity, black is no activity

throughout the Australian elapid radiation. Early major shifts occurred independently in the Pseudechis and Notechis clades and Elapognathus coronatus. We recorded four instances of late shifts in PLA $_{2}$ activity; Demansia vestigiata (Demansia clade), Denisonia maculata (Rhinoplocephalus/Suta clade), and Austrelaps ramsayi and Hoplocephalus bitorquatus (Notechis clade). This suggests that $\mathrm{PLA}_{2}$ is a dynamic protein family still under positive selection in some lineages. There were several instances of a decrease or loss of activity for this protein family - Tropidechis (decrease), Vermicella (almost complete loss) and Echiopsis (no detectable activity). The genus Pseudechis possessed the highest levels of activity for PLA P $_{2}$ We could find no evidence of correlation with any particular dietary categories to the activity for this protein family. Overall activity for this protein family was remarkably clade specific with only a small number of exceptions all in closely related species. These are discussed below:

Our results for the genus Hoplocephalus showed strong non-overlapping inter-specific variation in $\mathrm{PLA}_{2}$ activity for the three species, which co-varied with phylogenetic distance [43]. This was the only genus in our data set of 16 genera to show such a pattern. PLA 2 activity has diverged substantially in this genus, with extremely low activity levels detected in $H$. bungaroides and its sister species $H$. stephensi, while activity levels are substantially higher in $H$. bitorquatus. This suggests that the major decrease in $\mathrm{PLA}_{2}$ activity occurred after the divergence of $H$. bitorquatus and $H$.bungaroides/stephensi, but before the divergence of $H$. bungaroides. It would appear from this that the loss of a single protein family may not incur a significant fitness cost.

Another notable result in our analysis of $\mathrm{PLA}_{2}$ activity was the difference in activity between the sister species Denisonia devisi and D. maculata. These allopatric species are indistinguishable in scalation characters [44], and extremely similar in morphology (Fig. 7) and ecology [30]. However, there is no molecular data available to estimate their genetic distance. PLA $\mathrm{P}_{2}$ activity levels recorded in these two species showed an almost ten-fold difference with higher activity in D. maculata compared to $D$. devisi (Fig. 2.) These species show considerable dietary overlap ( $88 \%$ frogs for D. devisi and $95 \%$ frogs for $D$. maculata [30], so there is a possibility that the divergence in venom phenotypes between these two species may not have been driven by positive selection for diet.

These sister species with their near identical diets and foraging ecologies would make excellent candidates for testing the relative influence of genetic drift vs positive selection on 

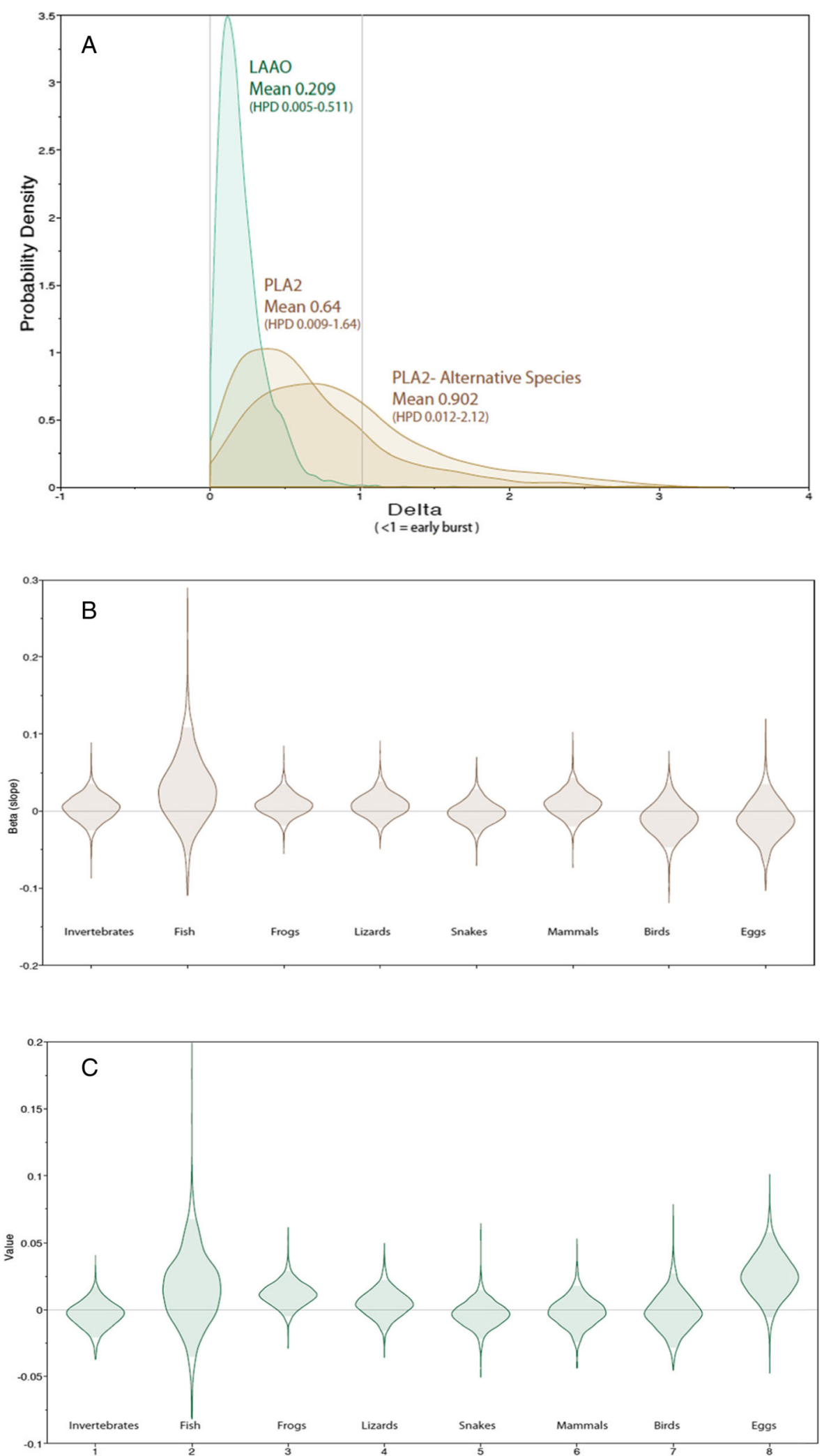

Fig. 6 (See legend on next page.) 
(See figure on previous page.)

Fig. 6 Testing for accelerated evolution of PLA $A_{2}$ and LAAO, and for correlation with diet, based on phylogenetic comparative methods in BayesTraits. (Upper) The delta parameter estimates for PLA $A_{2}$ and LAAO: values $<1$ indicate faster initial rates of change. We have included an adjusted PLA 2 profile (alternative species) with venom values for Denisonia maculata and Austrelaps ramsayi substituted for their sister-species, which changes our delta value from 0.64 to 0.9. (Middle and Lower) Regression coefficients (beta) values for PLA $A_{2}$ and LAAO when phylogenetically regressed against the proportions of eight dietary items. A beta of 0 indicates no correlation

venom. This could be done by quantifying the ratio of substitution rates at non-synonymous and synonymous sites $\omega$ (dN/dS ratios) known as likelihood ratio testing for positive selection. An $\omega$ ratio greater than one indicates positive selection [15]. The possibility of venom proteomes becoming radically "reset" onto new evolutionary trajectories due to genetic drift has received little attention in the literature and may have been underestimated.

We also found a marked divergence in PLA 2 activity between the sister-species Austrelaps ramsayi and $A$. superbus with $A$. ramsayi having activity four times higher (Fig. 2).

The difference in activity between the sister clades Acanthophis and Pseudechis may be explainable by the different foraging strategies of these two genera. Although both genera are dietary generalists, Acanthophis is perhaps the most highly divergent Australian terrestrial elapid in its morphology and ecology, while Pseudechis is a generalized forager lacking morphological specializations. As Acanthophis is a slow-moving ambush predator, its lower $\mathrm{PLA}_{2}$ activity may be the result of selection pressure favouring a faster acting protein family e.g. post-synaptic neurotoxins (3FTxs), which have been shown to be the dominant protein family in the venom proteome of this genus [6]. This may make Acanthophis an example of selection pressure for venom activity not being driven by diet, but dictated by the requirements of foraging strategy.

\section{LAAO activity}

LAAO activity showed greater clade specificity than activity levels of $\mathrm{PLA}_{2}$, suggesting that it is a more conservative protein family in Australian elapid venoms. LAAO showed early accelerated rates of change. This may indicate differential selection pressure as $\mathrm{PLA}_{2}$ is known to make up a much greater proportion of the venom proteome of nearly all snakes tested worldwide [3]. The early burst of evolution for LAAO accounts for the major differences in activity across the major elapid clades, but relatively smaller difference within them. In Demansia and Pseudechis, high activity has been retained in all species tested in these two genera. Activity is completely absent in the Vermicella and Pseudonajal Oxyuranus clades. The loss of activity for LAAO occurred before the divergence of these two clades supporting the molecular evidence for relationships among these disparate taxa. The Notechis clade showed a trend for decreasing activity for LAAO in the genera Austrelaps and Tropidechis, and a unique instance of a recent shift in this protein family in the genus Hoplocephalus. High LAAO activity was recorded for all three species of Hoplocephalus, suggesting that the increase in activity occurred early in the evolutionary history of this genus, before the divergence of the three species. The absence of LAAO activity in some individuals in the genera Parasuta and Suta, suggests that the loss of this protein family may not incur a significant fitness cost.

Our dietary analysis does show a slight correlation for high activity for this protein family with a frog diet, but there were several important exceptions to this e.g. Demansia psammophis and Hoplocephalus stephensi (see dietary table Additional file section). In addition, this may also be a chance finding considering the number of snakes and the number of different diets included in the analysis.

\section{Limitations}

Although this study represents the most comprehensive characterization of venom activity among Australian elapids

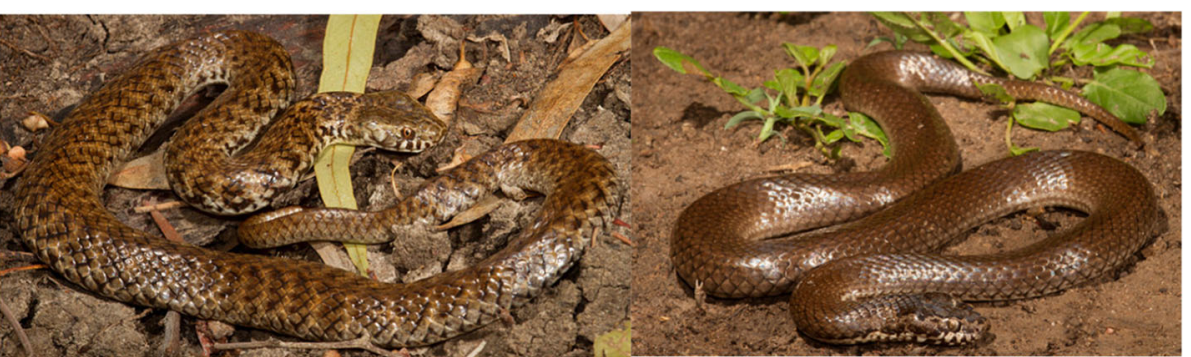

Fig. 7 Denisonia devisi (left) and D. maculata (right). These two closely related frog specialists from the eastern sub-interior of Australia are indistinguishable based on scalation characters. Despite their similar diets, they possess highly divergent PLA 2 activity. The process responsible for this divergence is currently unknown (Photos courtesy of Brendan Schembri) 
to date, incorporating almost all major clades, it still did not sample all species of Australian elapids, or representatives of every major clade. Additionally we were unable to obtain molecular data to clarify the divergence time between two sister species in the genus Denisonia which possessed different activities for $\mathrm{PLA}_{2}$. Another limitation was not being able to compare other important toxin families such as metalloproteases, serine proteases, three-finger toxins and disintegrins. Further, we only screened LAAO activity against L-leucine and not its full substrate repertoire, so its activity against other amino acids is unknown and potentially could alter the results presented here.

As the majority of the snakes used in the study were already being held in captivity, this raises the issue of venom activity/composition being altered due to captive conditions or artificial diet. Based on previously published studies this should not significantly impact the results of this study [45-47]. For example, a study on the Jararaca Bothrops jararaca [48] found that venom is not significantly influenced by captivity. Another study on the same species [49], found that electrophoretic profiles, enzymatic activity and lethality showed only minor differences between captive and wild-caught specimens. A study on the Australian eastern brown snake P. textilis [50] also found that captivity had limited effects on venom composition.

We would like to emphasize that although we found no correlation between activity of these two protein families and broad dietary categories, this does not rule out the possibility of toxins within these protein families being adapted for prey specific toxicity. This is almost certainly the case as it has been established that $\mathrm{PLA}_{2}$ activity in taipans is not correlated to toxicity [51, 52]. Our study is just establishing a strong correlation between catalytic activity and phylogeny, the lack of correlation we observed between activity and diet is likely to prove less informative.

\section{Materials}

\section{Snake venom}

The study included 91 individual snakes plus pooled venom from two species of 39 species of Australasian elapids from the approximately 100 species of the terrestrial Australian elapids. This represents 17 of the 24 genera and eight of the 11 currently recognized clades. The localities and collectors for each snake are listed in Additional file 1: Table S2 (Supplementary Section).

All snakes were maintained at Venom Supplies Tanunda South Australia. Only adult snakes were used for the project. After milking, venom was freeze-dried and the lyophilized venom was reconstituted the day of the experiments in millipure water for LAAO assays and 4-nitro-3-octanoyloxybenzoic acid (NOB) buffer for PLA2 assays. All venom used for the study was from individual snakes except for Oxyuranus temporalis (pooled from two individuals from Ilkurlka Roadhouse W.A.), and Oxyuranus microlepidotus (pooled from several individuals from Goyder's Lagoon S.A.). Most of the snakes used in the study were already in captive maintenance at Venom Supplies South Australia apart from two individuals of Hoplocephalus bungaroides in the private collection of Simon Tresseder Licence No. AKL 68528. The remaining 29 snakes were collected under the approval of animal ethics No A-2016-609 and scientific licences SL 101728 N.S.W. WISP 1747976 QLD and 08-000297 W.A. (Additional file 1: Table S1) (Snakes were transported by air to Venom Supplies, Tanunda South Australia.

\section{Reagents}

The following materials were used for the study: NOB (4-nitro-3-octanoyloxybenzoic acid) Cat. No. BMLST506-0050 Enzo Life Sciences, Leucine Pcode 1,001, 836,926 L8000-25G Sigma Life Sciences, o-Dianisidine Pcode 1,001,844,919 D9143-5G Sigma Life Sciences, Horseradish peroxidase Pcode 1,002,325,511 P67825MG Sigma Life Sciences, acetonitrile HPLC grade Item\# 20060.320 VWR chemicals, TRIS (Hydroxymethyl methylamine) 2311-500G Ajax Finechem, hydrogen peroxide UN No 2014 Biolab scientific, $\mathrm{NaOH}$ A482-500G Ajax Finechem.

For both assays reactions were monitored in a Synergy HT UV spectrophotometric plate reader, using Thermo Fischer Scientific 96 well clear-bottom microplates.

\section{Methods}

\section{Phospholipase $\mathrm{A} 2$ activity}

The protocol used followed Petrovic et al. 2001 [53]. $\mathrm{PLA}_{2}$ activity was measured using a kinetic assay that detects a chromogenic substrate NOB (4-nitro-3-octanoyloxy-benzoic acid). $\mathrm{PLA}_{2}$ enzymes cleave an ester bond resulting in the conversion of the NOB substrate to a fatty acid and the chromophore 4-nitro-3-hydrobenzoic acid. There is a linear relationship between the formation of the chromophore and absorbance which is monitored by a spectrophotometer.

Lyophilized venom was reconstituted in buffer at a concentration of $1 \mathrm{mg} / \mathrm{mL}$ or $100 \mu / \mathrm{mL}$, depending on the potency of the $\mathrm{PLA}_{2}$ activity for each venom. Buffer solution was made up from $1 \mathrm{~mL} 1 \mathrm{M}$ Tris buffer $(\mathrm{pH}$ 8.4), $2.5 \mathrm{~mL} 4 \mathrm{M} \mathrm{NaCl}$, and $2.5 \mathrm{~mL} 0.4 \mathrm{M} \mathrm{CaCl}_{2}$, made up to $100 \mathrm{~mL}$ with millipure water. $\mathrm{NOB}$ substrate was reconstituted in acetonitrile at a concentration of $4 \mathrm{mg} /$ $\mathrm{mL}$. The buffer solution and the NOB substrate were mixed at a ratio 85:15 NOB buffer/NOB substrate. We used $100 \mu \mathrm{L}$ of buffer solution as a negative control and $100 \mu \mathrm{L}$ of Pseudechis australis venom as a positive control. $P$. australis was chosen as a positive control because 
its venom is known to contain large amounts of $\mathrm{PLA}_{2}$ toxins and preliminary assays showed it possessed high levels of $\mathrm{PLA}_{2}$ activity. Venom sample $(100 \mu \mathrm{L})$ was added to five wells (to give $n=5$ ) in a single column of a microplate, and in five wells in the adjoining column were added $100 \mu \mathrm{L}$ of the NOB buffer/substrate mixture. This was preheated in a spectrophotometer at $37^{\circ}$ for $10 \mathrm{~min}$. The venom was then added to the NOB buffer/ substrate mixture and the reaction monitored every $30 \mathrm{~s}$ at $425 \mathrm{~nm}$. The negative control absorbance measurements were subtracted from the absorbance measurements for the venom at the $10 \mathrm{~min}$ reading and the 0 min reading.

The equation obtained from the standard curve was then used to calculate the amount of chromophore generated and this value was divided by 10 to give nanomoles of product released per minute per $\mathrm{mg}$ of venom.

A standard curve of the amount of NOB product produced versus absorbance was created by alkaline hydrolysis using $4 \mathrm{M} \mathrm{NaOH}$. Well A of a microplate was filled with $90 \mu \mathrm{L}$ of water, $100 \mu \mathrm{L}$ of $4 \mathrm{M} \mathrm{NaOH}$ and $10 \mu \mathrm{L}$ of NOB substrate. The reaction was monitored in a spectrophotometer for $30 \mathrm{~min}$ until a stable plateau was apparent. The remaining wells in the column were then filled with $100 \mu \mathrm{L}$ of diluent (mixture ratio $900 \mu \mathrm{L}$ of water, $1 \mathrm{~mL} \mathrm{NaOH}$ and $100 \mu \mathrm{L}$ acetonitrile). $100 \mu \mathrm{L}$ of well A was then serially diluted 1:1 into the wells of the column. Absorbance was measured on a spectrophotometer. From the molecular weight of NOB substrate (309.3) and the amount applied to the well (conc. $4 \mathrm{mg} /$ $\mathrm{mL}$ ) we determined the amount per well in nanomoles. This gave the equation $\mathrm{y}=0.0149 \mathrm{X}+0.0524$.

The standard curve was re-created $n=9(n=3$ over 3 days), to check standard error at all points. Minimum resolution was determined to be 0.05 absorbance units (see Additional file section). Results were graphed using GraphPad Prism.

\section{L-amino acid oxidase activity}

The protocol used followed Kishimoto and Takahashi 2001 [54]. The assay uses leucine as a substrate for the LAAO toxin in the venom which produces hydrogen peroxide and ammonia. A reagent mixture containing orthodianisidine and horse-radish peroxidase (HRP) is added. The hydrogen peroxide oxidizes the o-dianisidine to a coloured product, this is measured spectrophotometrically in a microplate reader at $450 \mathrm{~nm}$.

Lyophilized venom was reconstituted in millipure water at a concentration of $100 \mu \mathrm{g} / \mathrm{mL}$. The reagent mixture was made at the following ratio; leucine $600 \mu \mathrm{L}$, Odianisidine $1.2 \mathrm{~mL}, \mathrm{HRP} 120 \mu \mathrm{L}$ and $25 \mathrm{mM}$ Tris buffered saline $\mathrm{pH} 8.46 \mathrm{~mL}$.

The venom samples $(100 \mu \mathrm{g} / \mathrm{mL})$ were added to five wells (to give $n=5$ ), in a single column of a 96 well microplate at a volume of $50 \mu \mathrm{L}$ per well. $200 \mu \mathrm{L}$ of reagent mixture was added to five wells in an adjoining column. The plate was then pre-heated at $37^{\circ} \mathrm{C}$ for 10 min in a spectrophotometer and the venom then added to the reagent mixture to start the reaction. The reaction was monitored once per min for $10 \mathrm{~min}$. A negative control well contained $50 \mu \mathrm{L}$ of Tris and a positive control well contained $50 \mu \mathrm{L}$ of Pseudechis australis venom. This species was chosen as a positive control as preliminary assays showed it possessed high levels of LAAO activity. The negative control absorbance measurements were subtracted from the absorbance measurements for the venom at the $10 \mathrm{~min}$ reading and the 0 min reading.

The equation obtained from a standard curve was then used to calculate the amount of $\mathrm{H}_{2} \mathrm{O}_{2}$ generated and this value was divided by 10 to give nanomoles of $\mathrm{H}_{2} \mathrm{O}_{2}$ produced per minute per $\mathrm{mg}$ of venom $(\mathrm{nmol} / \mathrm{min} / \mathrm{mg})$. Results were then graphed using GraphPad Prism.

A standard curve was created using $\mathrm{H}_{2} \mathrm{O}_{2} 9.79 \mathrm{M}$. This was diluted 1:10000 in millipure water to give a concentration of $0.979 \mathrm{mM} .50 \mu \mathrm{L}$ of water were placed in wells B to $\mathrm{H}$. To well A was added $50 \mu \mathrm{L}$ of diluted $\mathrm{H}_{2} \mathrm{O}_{2}$. To well $B$ was added $50 \mu \mathrm{L}$ of diluted $\mathrm{H}_{2} \mathrm{O}_{2}$, which was then serially diluted $1: 1$ to wells $B$ to $G$. All wells in the adjoining column contained $200 \mu \mathrm{L}$ of the same reagent mixture used for the venom assays. The plate was preheated at $37^{\circ} \mathrm{C}$ for $10 \mathrm{~min}$ and the two columns then mixed. Absorbance was monitored for $10 \mathrm{~min}$ at $450 \mathrm{~nm}$. Amount of $\mathrm{H}_{2} \mathrm{O}_{2}$ in well A was calculated at $48.95 \mathrm{nmol}$. The amounts in the serially diluted wells were calculated from this and standard curve was created in GraphPad Prism giving the eq. $0.0276 \mathrm{x}+0.01899$. The standard curve was performed in triplicate.

\section{Comparative analyses of temporal dynamics and correlated evolution of PLA $A_{2}$ and LAAO profiles}

For all analyses, mean PLA 2 and LAAO activity levels for each species were used and logged to base 10 (after addition of 1 to avoid attempting to log 0 values); diet proportions were arcsine transformed [55]. To trace evolutionary changes in PLA2 and LAAO activity levels, these two variables were optimised on the most recent dated phylogeny of elapids (Lee et al. 2015), which included 28 of the species evaluated here. The relationships and divergence dates between these 28 species were derived by pruning out irrelevant taxa. Linear parsimony, squarechange parsimony and maximum likelihood, as implemented in Mesquite [56], were used to reconstruct ancestral states at nodes and changes along branches. As all methods retrieved broadly similar patterns, the results and discussion focuses on the linear parsimony results.

To test whether rates of change in PLA2 and LAAO activity levels have been constant through time, or were faster/slower during the early phases of the elapid radiation, 
we implemented the delta transformation in BayesTraits, which either compresses or lengthens basal branches [57]. A delta of less than 1 indicates faster early rates of change, consistent with an early burst model. To evaluate whether changes in PLA2 and LAAO activity levels were correlated with shifts in diet, we obtained diet information for these 28 species from Shine [29-32, 35, 36, 38-41, 58-62], expressed as proportions of eight categories (invertebrates, fish, frogs, lizards, snakes, mammals, birds and eggs - see Additional file 1: Table S1 - Additional file Section). Phylogenetic comparative methods, implemented in BayesTraits continuous regression model, was used to test whether PLA2 or LAAO activity levels were correlated with any of these four diet items. A regression coefficient (beta) which is indistinguishable from 0 means no correlation.

All BayesTraits analyses used Markov-Chain Monte Carlo to infer the probability distribution of the target parameters, and analyses were repeated twice to confirm stationarity, with the results from both runs concatenated in Tracer [63] to generate mean and HPD statistics. The raw and transformed values for all these variables, and scripts for all analyses, are appended in Supplementary Information.

\section{Supplementary information}

Supplementary information accompanies this paper at https://doi.org/10. 1186/s12862-020-1578-x.

Additional file 1: Table S1. Diet of Australian elapids taken mainly from Shine. Table S2. Location sites and collectors for all snakes used in the study. Figure S1. PLA2 activity reconstructed using square-change parsimony, analytically equivalent to a special case of likelihood [42], on a phylogeny [1] of 16 of the 17 genera tested (27 of the 37 species; Hemiaspis has no PLA2 data). The Y-axis represents millions of years before present. Values had 1 added before log transformation (to avoid attempting to log 0 values, as any species with activity below the threshold of detection of 0.5 - unlogged value - was allocated a score of 0 ). Dotted vertical lines separate clades. Warmer colours (red) show higher activity; black is no activity; white is extreme uncertainty due to missing data in Hemiaspis. Figure S2. LAAO activity reconstructed using linear parsimony on a phylogeny [1] for all 17 genera tested (28 of the 39 species for which activity was measured). Y-axis represents millions of years before present. Values had 1 added before log transformation (to avoid attempting to log 0 values, as any species with activity below the threshold of detection of 0.5 - unlogged value - was allocated a score of 0 ). Dotted vertical lines separate clades. Warmer colours (red) show higher activity, black is no activity.

\section{Abbreviations}

HPD: highest posterior density; LAAO: L-amino acid oxidase; nmol/min/ $\mathrm{mg}$ : nanomoles of chromophore produced per minute per milligram of venom; PLA $A_{2}$ : Phospholipase $A_{2}$

\section{Acknowledgements}

Theo Tasoulis would like to thank Richie Gilbert for both snake collecting and for introducing him to his network of snake catching friends across Australia who provided many of the more obscure species used in the study; Brian Bush, Callan Crigan, Ross McGibbon, Brendan Schembri. Thanks also to Dr. Margaret O'Leary for expert advice in performing LAAO assays. Simon Tresseder for providing venom from his captive specimens of Hoplocephalus bungaroides. Thanks also to the snake catchers Kylee Gray, and Stephen Mahony. Special thanks to Brian Bush. Thanks to Brendan Schembri for use of his beautiful photographs.

\section{Authors' contributions}

$\Pi T$ and GKI conceived the project and study design; $T$ and $M Z$ performed the assays and data processing; $T$, MZ, ML, JS and GKI analysed the data; ML performed statistical analysis and developed the cladograms; ND housed and milked individual snakes; TT and GKI wrote the manuscript with all authors reviewing the drafts. GKI takes responsibility for the manuscript. All authors read and approved the final Manuscript.

\section{Funding}

Geoff Isbister is funded by an National Health and Medical Research Council Senior Research Fellowship ID1061041. The funding body played no role in the design of the study and collection, analysis, and interpretation of data and in writing the manuscript.

\section{Availability of data and materials}

The datasets used and/or analysed during the current study are available from the corresponding author on reasonable request.

\section{Ethics approval and consent to participate}

All snakes were collected for venom milking with approval from the University of Newcastle Animal Care and Ethics Committee (Approval: A2016-609) and scientific licences from State Wildlife services: SL 101728 (NSW), WISP 1747976 (QLD) and 08-000297 (WA).

\section{Consent for publication}

Not applicable.

\section{Competing interests}

The authors declare that they have no competing interests.

\section{Author details}

${ }^{1}$ Clinical Toxicology Research Group, University of Newcastle, Newcastle, New South Wales 2308, Australia. Earth Sciences Section, South Australian Museum, North Terrace, Adelaide, S.A 5000, Australia. ${ }^{3}$ College of Science and Engineering, Flinders University, Bedford Park, S.A 5042, Australia. ${ }^{4}$ Venom Supplies, Tanunda, South Australia 5352, Australia. ${ }^{5}$ Museums Victoria, Carlton Gardens, Carlton, VIC 5053, Australia.

Received: 12 December 2018 Accepted: 6 January 2020

Published online: 13 January 2020

\section{References}

1. Lee MS, Sanders KL, King B, Palci A. Diversification rates and phenotypic evolution in venomous snakes (Elapidae). R Soc Open Sci. 2016;3(1):150277.

2. Jackson TN, Koludarov I, Ali SA, Dobson J, Zdenek CN, Dashevsky D, et al. Rapid Radiations and the Race to Redundancy: An Investigation of the Evolution of Australian Elapid Snake Venoms. Toxins (Basel). 2016;8:11.

3. Tasoulis T, Isbister GK. A review and database of Snake venom proteomes. Toxins (Basel). 2017:9(9):290.

4. Kang TS, Georgieva D, Genov N, Murakami MT, Sinha M, Kumar RP, et al. Enzymatic toxins from snake venom: structural characterization and mechanism of catalysis. FEBS J. 2011;278(23):4544-76.

5. Kuruppu S, Reeve S, Banerjee Y, Kini RM, Smith Al, Hodgson WC. Isolation and pharmacological characterization of cannitoxin, a presynaptic neurotoxin from the venom of the Papuan Taipan (Oxyuranus scutellatus canni). J Pharmacol Exp Ther. 2005;315(3):1196-202.

6. Fry BG, Wickramaratna JC, Hodgson WC, Alewood PF, Kini RM, Ho H, et al. Electrospray liquid chromatography/mass spectrometry fingerprinting of Acanthophis (death adder) venoms: taxonomic and toxinological implications. Rapid Commun Mass Spectrom. 2002;16(6):600-8.

7. Whittington AC, Mason AJ, Rokyta DR. A single mutation unlocks cascading Exaptations in the origin of a potent Pitviper neurotoxin. Mol Biol Evol. 2018;35(4):887-98

8. Wickramaratna JC, Fry BG, Aguilar MI, Kini RM, Hodgson WC. Isolation and pharmacological characterization of a phospholipase A2 myotoxin from the venom of the Irian Jayan death adder (Acanthophis rugosus). $\mathrm{Br} J$ Pharmacol. 2003;138(2):333-42.

9. Lane J, O'Leary MA, Isbister GK. Coagulant effects of black snake (Pseudechis spp.) venoms and in vitro efficacy of commercial antivenom. Toxicon. 2011; 58(3):239-46. 
10. Lazo F, Vivas-Ruiz DE, Sandoval GA, Rodriguez EF, Kozlova EEG, CostalOliveira F, et al. Biochemical, biological and molecular characterization of an L-amino acid oxidase (LAAO) purified from Bothrops pictus Peruvian snake venom. Toxicon. 2017:139:74-86.

11. Wei JF, Yang HW, Wei XL, Qiao LY, Wang WY, He SH. Purification, characterization and biological activities of the L-amino acid oxidase from Bungarus fasciatus snake venom. Toxicon. 2009;54(3):262-71.

12. Izidoro LF, Sobrinho JC, Mendes MM, Costa TR, Grabner AN, Rodrigues VM et al. Snake venom L-amino acid oxidases: trends in pharmacology and biochemistry. Biomed Res Int. 2014;2014:196754.

13. Dashevsky D, Debono J, Rokyta D, Nouwens A, Josh P, Fry BG. Three-finge toxin diversification in the venoms of cat-eye snakes (Colubridae: Boiga). J Mol Evol. 2018:86(8):531.

14. Jackson TN, Sunagar K, Undheim EA, Koludarov I, Chan AH, Sanders K, et al. Venom down under: dynamic evolution of Australian elapid snake toxins. Toxins (Basel). 2013;5(12):2621-55.

15. Sunagar K, Jackson TN, Undheim EA, Ali SA, Antunes A, Fry BG. Threefingered RAVERs: rapid accumulation of variations in exposed residues of snake venom toxins. Toxins (Basel). 2013;5(11):2172-208.

16. Mitchell KE, Schultz BD. Looking good from this window. Science. 1999; 283(5405):1131-2

17. Yang ZM, Xie YZ, Yan SX, Liu ZZ, Song JC, Wang ZZ, et al. Tracing the evolution of venom phospholipases A2 in Gloydius strauchii and related pitvipers: a tale of two acidic isozymes. Toxicon. 2018;141:65-72.

18. Casewell NR. On the ancestral recruitment of metalloproteinases into the venom of snakes. Toxicon. 2012;60(4):449-54.

19. Casewell NR, Wagstaff SC, Harrison RA, Renjifo C, Wuster W. Domain loss facilitates accelerated evolution and neofunctionalization of duplicate snake venom metalloproteinase toxin genes. Mol Biol Evol. 2011;28(9):2637-49.

20. Sunagar K, Johnson WE, O'Brien SJ, Vasconcelos V, Antunes A. Evolution of CRISPS associated with toxicoferan-reptilian venom and mammalian reproduction. Mol Biol Evol. 2012;29(7):1807-22.

21. Calvete JJ, Escolano J, Sanz L. Snake venomics of Bitis species reveals large intragenus venom toxin composition variation: application to taxonomy of congeneric taxa. J Proteome Res. 2007;6(7):2732-45.

22. Wittenberg RD, Jadin RC, Fenwick AM, Gutberlet RL. Recovering the evolutionary history of Africa's most diverse viper genus: morphological and molecular phylogeny of Bitis (Reptilia: Squamata: Viperidae). Org Divers Evol. 2014;15(1):115-25.

23. Barlow A, Pook CE, Harrison RA, Wuster W. Coevolution of diet and preyspecific venom activity supports the role of selection in snake venom evolution. Proc Biol Sci. 2009;276(1666):2443-9.

24. Starkov VG, Osipov AV, Utkin YN. Toxicity of venoms from vipers of Pelias group to crickets Gryllus assimilis and its relation to snake entomophagy. Toxicon. 2007;49(7):995-1001.

25. Savidge JA. Food habits of Boiga irregularis, an introduced predator on Guam. J Herpetol. 1988;22:275.

26. Mackessy SP, Sixberry NM, Heyborne WH, Fritts T. Venom of the Brown Treesnake, Boiga irregularis: ontogenetic shifts and taxa-specific toxicity. Toxicon. 2006:47(5):537-48

27. Williams $V$, White J, Schwaner TD, Sparrow A. Variation in venom proteins from isolated populations of tiger snakes (Notechis ater niger, N. scutatus) in South Australia. Toxicon. 1988;26(11):1067-75.

28. Williams $\vee$, White J. Variation in venom constituents within a single isolated population of peninsula Tiger Snake (Notechis-Ater Niger). Toxicon. 1987; 25(11):1240-3.

29. Shine R. Food-habits and reproductive-biology of small Australian snakes of the genera Unechis and Suta (Elapidae). J Herpetol. 1988;22(3):307-15.

30. Shine R. Food-habits and reproductive-biology of Australian elapid snakes of the genus Denisonia. J Herpetol. 1983;17(2):171-5.

31. Shine R. Reproductive-biology and food-habits of the Australian elapid snakes of the genus Cryptophis. J Herpetol. 1984;18(1):33-9.

32. Shine R. Ecology of eastern Australian Whipsnakes of the genus-Demansia. Herpetol. 1980;14(4):381-9.

33. Shine R. Comparative ecology of three Australian Snake species of the genus Cacophis (Serpentes:Elapidae). Copeia. 1980;1980(4):831-8.

34. Shine R. Ecology of Australian elapid snakes of the genera Furina and Glyphodon. J Herpetol. 1981;15(2):219-24.

35. Shine R. Food-habits and reproductive-biology of Australian snakes of the genus Hemiaspis (Elapidae). J Herpetol. 1987;21(1):71-4.

36. Shine $\mathrm{R}$, Covacevich J. Ecology of highly venomous snakes - the Australian genus Oxyuranus (Elapidae). J Herpetol. 1983;17(1):60-9.
37. Scanlon JD, Shine R. Dentition and diet in snakes - adaptations to Oophagy in the Australian elapid genus Simoselaps. J Zool. 1988;216(3):519-28.

38. Shine R. Reproduction, feeding and growth in the Australian burrowing Snake Vermicella-Annulata. J Herpetol. 1980;14(1):71-7.

39. Shine R. Ecology of the Australian elapid Snake Echiopsis-Curta. J Herpetol. 1982;16(4):388-93.

40. Shine R. The evolution of Viviparity - ecological correlates of reproductive mode within a genus of Australian snakes (Pseudechis, Elapidae). Copeia. 1987;1987(3):551-63.

41. Shine R. Habitats, diets, and sympatry in snakes: a study from Australia. Can J Zool. 1977:55(7):1118-28.

42. Maddison WP. Squared-change parsimony reconstructions of ancestral states for continuous-valued characters on a phylogenetic tree. Syst Biol. 1991;40(3):304-14

43. Sumner J, Webb JK, Shine R, Keogh JS. Molecular and morphological assessment of Australia's most endangered snake, Hoplocephalus bungaroides, reveals two evolutionarily significant units for conservation. Conserv Genet. 2009;11(3):747-58.

44. Cogger H. Reptiles and amphibians of Australia. Melbourne: CSIRO Publishing; 2014.

45. Rex CJ, Mackessy SP. Venom composition of adult Western diamondback rattlesnakes (Crotalus atrox) maintained under controlled diet and environmental conditions shows only minor changes. Toxicon. 2019:164:51-60.

46. Daltry JC, Ponnudurai G, Shin CK, Tan N-h, Thorpe RS, Wolfgang W. Electrophoretic profiles and biological activities: intraspecific variation in the venom of the malayan pit viper (Calloselasma rhodostoma). Toxicon. 1996; 34(1):67-79.

47. Margres MJ, Wray KP, Seavy M, McGivern JJ, Sanader D, Rokyta DR. Phenotypic integration in the feeding system of the eastern diamondback rattlesnake (Crotalus adamanteus). Mol Ecol. 2015:24(13):3405-20.

48. Galizio NC, Serino-Silva C, Stuginski DR, PAE A, Sant'Anna SS, Grego KF, et al. Compositional and functional investigation of individual and pooled venoms from long-term captive and recently wild-caught Bothrops jararaca snakes. J Proteome. 2018:186:56-70.

49. IBd F, Morais-Zani K, Serino-Silva C, Sant'Anna SS, MMTd R, Grego KF, et al. Functional and proteomic comparison of Bothrops jararaca venom from captive specimens and the Brazilian Bothropic reference venom. J Proteome. 2018;174:36-46.

50. McCleary RJ, Sridharan S, Dunstan NL, Mirtschin PJ, Kini RM. Proteomic comparisons of venoms of long-term captive and recently wild-caught eastern brown snakes (Pseudonaja textilis) indicate venom does not change due to captivity. J Proteome. 2016;144:51-62.

51. Lambeau G, Barhanin J, Schweitz H, Qar J, Lazdunski M. Identification and properties of very high affinity brain membrane-binding sites for a neurotoxic phospholipase from the taipan venom. J Biol Chem. 1989. 264(19):11503-10.

52. Rouault M, Rash LD, Escoubas $\mathrm{P}$, Boilard $\mathrm{E}$, Bollinger J, Lomonte $\mathrm{B}$, et al. Neurotoxicity and other pharmacological activities of the snake venom phospholipase A2 OS2: the N-terminal region is more important than enzymatic activity. Biochemistry. 2006;45(18):5800-16.

53. Petrovic N, Grove C, Langton PE, Misso NLA, Thompson PJ. A simple assay for a human serum phospholipase A2 that is associated with high-density lipoproteins. J Lipid Res. 2001:42(10):1706-13.

54. Kishimoto M, Takahashi T. A spectrophotometric microplate assay for Iamino acid oxidase. Anal Biochem. 2001:298(1):136-9.

55. McDonald JH. Handbook of biological statistics. 3rd ed. Baltimore, Maryland: Sparky House Publishing; 2014

56. The Mesquite Project Team 2018. Documentation for Mesquite: a modular system for evolutionary analysis. http://www.mesquiteproject.org.

57. Pagel M, Meade A. BayesTraits V3.0.01. http://wwwevolutionrdgacuk/ BayesTraits.V3001.html. 2017

58. Shine R. Arboreality in snakes - ecology of the Australian elapid genus Hoplocephalus. Copeia. 1983;1983(1):198-205

59. Shine R. Constraints, allometry, and adaptation: food habits and reproductive biology of Australian Brown snakes (Pseudonaja: Elapidae). Herpetologica. 1989:45(2):195-207.

60. Shine R. Ecological ramifications of prey size - food-habits and reproductivebiology of Australian copperhead snakes (Austrelaps, Elapidae). J Herpetol. 1987;21(1):21-8

61. Shine R, Charles N. Ecology of the Australian elapid Snake TropidechisCarinatus. J Herpetol. 1982;16(4):383-7. 
62. Shine R, Spencer CL, Keogh JS. Morphology, reproduction and diet in Australian and Papuan death adders (Acanthophis, Elapidae). PLoS One. 2014;9(4):e94216.

63. Rambaut A, Drummond AJ, Xie D, Baele G, Suchard MA. Posterior summarization in Bayesian Phylogenetics using tracer 1.7. Syst Biol. 2018; 67(5):901-4.

\section{Publisher's Note}

Springer Nature remains neutral with regard to jurisdictional claims in published maps and institutional affiliations.

- fast, convenient online submission

- thorough peer review by experienced researchers in your field

- rapid publication on acceptance

- support for research data, including large and complex data types

- gold Open Access which fosters wider collaboration and increased citations

- maximum visibility for your research: over $100 \mathrm{M}$ website views per year

At $\mathrm{BMC}$, research is always in progress. 